\title{
Brittleness of Zr-based bulk metallic glass matrix composites containing ductile dendritic phase
}

\author{
Y.F. Sun ${ }^{\mathrm{a}, \mathrm{b}, *}$, S.K. Guan ${ }^{\mathrm{a}}$, B.C. Wei ${ }^{\mathrm{b}}$, Y.R. Wang ${ }^{\mathrm{b}}$, C.H. Shek ${ }^{\mathrm{c}}$ \\ ${ }^{a}$ Research Center for Materials, Department of Materials and Engineering, Zhengzhou University, 450002 Zhengzhou, China \\ ${ }^{\mathrm{b}}$ National Microgravity Laboratory, Institute of Mechanics, CAS, Beijing 100080, China \\ ${ }^{\mathrm{c}}$ Department of Physics and Materials Science, City University of Hong Kong, 83 Tat Chee Avenue, Kowloon Tong, Hong Kong, China
}

Received in revised form 1 June 2005; accepted 1 June 2005

\begin{abstract}
$\mathrm{Zr}_{63} \mathrm{Al}_{10} \mathrm{Ni}_{10} \mathrm{Cu}_{14} \mathrm{Nb}_{3}$ monolithic bulk metallic glass (BMG) and $\mathrm{Zr}_{55} \mathrm{Al}_{8.5} \mathrm{Ni}_{8.5} \mathrm{Cu}_{13} \mathrm{Nb}_{15}$ BMG matrix composite containing densely distributed bcc dendritic phase were prepared by copper mould casting. The ductility of the dendritic phase was verified by nanoindentation tests. However, the composite samples exhibit relatively lower yield strength and no plastic strain under room temperature compression test. Microstructural characterization and fractography studies reveal that the simultaneous formation of quasicrystalline phase on the outermost region of the composite results in the brittleness of the composites.
\end{abstract}

(C) 2005 Elsevier B.V. All rights reserved.

Keywords: Metallic glass; Composites; Ductility; Mechanical properties

\section{Introduction}

With the development of bulk metallic glasses (BMGs) in many alloy families, such as $\mathrm{Pd}-, \mathrm{Zr}-, \mathrm{Fe}-, \mathrm{La}-, \mathrm{Mg}-, \mathrm{Ni}-$ and $\mathrm{Cu}$-based systems. BMGs acting as matrix materials for composites have attracted tremendous attention because of their relatively low melting points and high resistance to heterogeneous nucleation of crystals. The fabrication of BMG matrix composites is often considered a useful way to improve the plasticity of the monolithic BMG and expand its potential application as engineering materials. BMG composites reinforced with refractory metals or metal fibers, ceramic particles or carbon nano-tube have already been found to exhibit higher fracture strength and plastic deformation than that of its corresponding single phase BMG [1-7]. Recently, Hays et al. developed $\mathrm{Zr}-\mathrm{Ti}-\mathrm{Nb}-\mathrm{Cu}-\mathrm{Ni}-\mathrm{Be}$ BMG composites containing in situ formed ductile bcc typed $\beta$-Ti dendritic phase, which can be identified as crystalline $\mathrm{Ti}-\mathrm{Zr}-\mathrm{Nb}$ solid solute and deformed via plastic deformation mechanisms such as dislocation motion and twining [8-11]. The dendritic phase in

\footnotetext{
* Corresponding author. Tel.: +86 371 63887506; fax: +86 37163887508. E-mail address: yfsun@zzu.edu.cn (Y.F. Sun).
}

the BMG composites is suggested to contribute to the strainhardening and initiate multiple shear bands under loading, while the glass matrix provides high strength. Shortly after this, several in situ Be-free Zr- and Ti-based metallic composites containing ductile dendritic phase have been successfully fabricated. These composites combine the high strength of the glass matrix and the ductility of the bcc precipitates, and therefore exhibit remarkably improved mechanical properties [12-16]. This give rise to an idea that among the different kinds of BMG composites, those prepared via in situ processing, i.e., by precipitation of ductile micrometer-sized phases upon cooling from the melt, seem to be most promising [16]. However, the formation of the dendritic phase is strongly dependent on the composition and cooling rate of the glass forming alloys. For example, a small additional content of $\mathrm{Nb}$ only improves the glass-forming ability of the $\mathrm{Zr}-\mathrm{Al}-\mathrm{Ni}-\mathrm{Cu}$ BMG. But for higher $\mathrm{Nb}$ content and lower contents of $\mathrm{Cu}, \mathrm{Ni}$ and $\mathrm{Al}$, the glass forming ability decreases and the formation of dendritic phases is promoted.

In this paper, we present a $\mathrm{Zr}_{55} \mathrm{Al}_{8.5} \mathrm{Ni}_{8.5} \mathrm{Cu}_{13} \mathrm{Nb}_{15} \mathrm{BMG}$ composites containing large volume fraction of bcc dendritic phase. The dendritic phase shows obvious ductility under nanoindentation tests. However, the composites exhibit 
abnormally lower yield strength and zero globe plasticity under room temperature compression test. The mechanism of the deformation behavior was investigated and discussed.

\section{Experimental procedure}

Two alloys with different nominal compositions of $\mathrm{Zr}_{63} \mathrm{Al}_{10} \mathrm{Ni}_{10} \mathrm{Cu}_{14} \mathrm{Nb}_{3}$ and $\mathrm{Zr}_{55} \mathrm{Al}_{8.5} \mathrm{Ni}_{8.5} \mathrm{Cu}_{13} \mathrm{Nb}_{15}$ were prepared by copper mold cast, respectively. For getting a homogeneous master alloy, $\mathrm{Nb}$ and $\mathrm{Zr}$ metals are first arc melted to produce an intermediate binary $\mathrm{Zr}-\mathrm{Nb}$ alloy, followed by arc melting the mixture of the intermediate alloy and the other pure metals. Alloy rods with $3 \mathrm{~mm}$ in diameter and $70 \mathrm{~mm}$ in length were formed by arc melting the master alloys and then suction cast into a water-cooled copper mold.

The phase constitution of the as-cast samples was analyzed by X-ray diffraction (XRD) using a Siemens D500/501 diffractometer with $\mathrm{Cu} \mathrm{K} \alpha$ radiation. The thermal stability was examined by differential scanning calorimetry (DSC) in a flowing argon atmosphere with a heating rate of $20 \mathrm{~K} / \mathrm{min}$. Scanning electron microscopy (SEM) investigations and energy dispersive X-ray spectroscopy (EDX) microanalysis were performed using a Jeol 5200 SEM equipped with an Oxford energy dispersive X-ray spectrometer. Transmission electron microscopy (TEM) was carried out with a Philips TECNAI 20 electron microscope, operating at $200 \mathrm{kV}$. The TEM samples were first mechanically ground to a $30 \mu \mathrm{m}$ plate and then electropolished using a solution mixed in the ratio $\mathrm{HF}: \mathrm{HClO}_{4}: \mathrm{CH}_{4} \mathrm{O}=1: 1: 9$. Room temperature uniaxial compression tests were conducted under quasistatic loading (strain rate of $1 \times 10^{-4}$ ) with an Instron 5567 device. The samples with an aspect ratio of about 2:1 were prepared for the compression test. The nanoindentation tests were carried out with a constant loading rate of $50 \mathrm{mN} / \mathrm{min}$ on a nanoindenter supplied by CSM Instruments SA in Switzerland. The probe used was a Berkovich tip (CSM Instrument SA, Peseux, Switzerland).

\section{Experimental results}

The XRD patterns of the two as-cast alloys samples are shown in Fig. 1. For $\mathrm{Zr}_{63} \mathrm{Al}_{10} \mathrm{Ni}_{10} \mathrm{Cu}_{14} \mathrm{Nb}_{3}$ alloy in Fig. 1(a), a typical broad hump is observed with no visible crystalline diffraction peak, indicating the formation of fully amorphous microstructure. For $\mathrm{Zr}_{55} \mathrm{Al}_{8.5} \mathrm{Ni}_{8.5} \mathrm{Cu}_{13} \mathrm{Nb}_{15}$ alloys in Fig. 1(b), there are some obvious crystalline diffraction peaks on the XRD curves. Comparing with the phase constitution of bcc dendritic $\beta$-Ti phase reinforced Be-free $\mathrm{Zr}$-based BMG composites in refs. [12,13], these crystalline diffraction peaks can be easily identified as bcc phase. The formation of the bcc phase is also verified by microstructure characterization in later section.

Fig. 2 shows the DSC scans of the two as-cast alloys samples. A distinct glass transition with a supercooled liquid

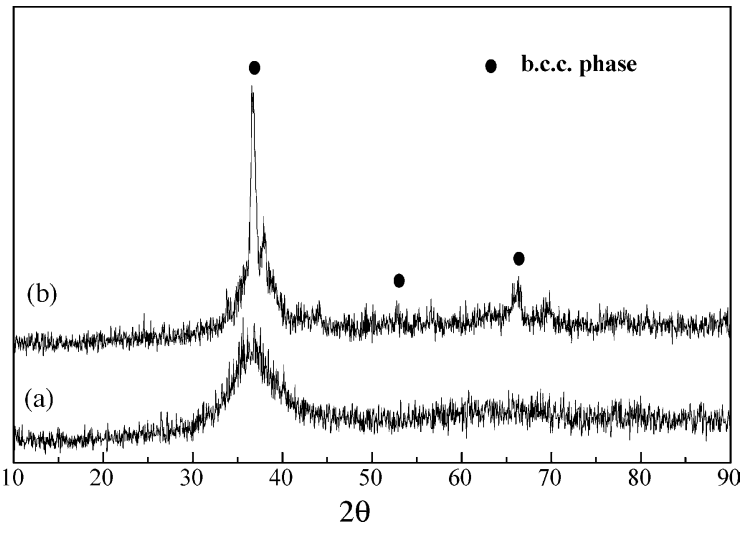

Fig. 1. XRD pattern of the as-cast alloys: (a) monolithic $\mathrm{Zr}_{63} \mathrm{Al}_{10}$ $\mathrm{Ni}_{10} \mathrm{Cu}_{14} \mathrm{Nb}_{3}$ BMG and (b) $\mathrm{Zr}_{55} \mathrm{Al}_{8.5} \mathrm{Ni}_{8.5} \mathrm{Cu}_{13} \mathrm{Nb}_{15}$ BMG composite containing bec phase.

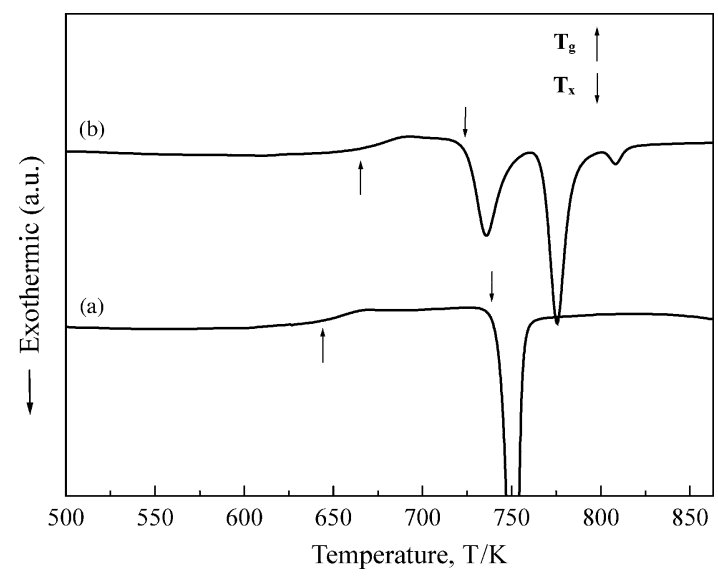

Fig. 2. DSC scans recorded for: (a) monolithic $\mathrm{Zr}_{63} \mathrm{Al}_{10} \mathrm{Ni}_{10} \mathrm{Cu}_{14} \mathrm{Nb}_{3} \mathrm{BMG}$ and (b) $\mathrm{Zr}_{55} \mathrm{Al}_{8.5} \mathrm{Ni}_{8.5} \mathrm{Cu}_{13} \mathrm{Nb}_{15}$ BMG composites containing bcc phase.

region, defined as the temperature span between the glass transition temperature $T_{\mathrm{g}}$ and the crystallization temperature $T_{\mathrm{x}}$, can be observed for both samples. However, the $T_{\mathrm{g}}$ shift to higher temperature and the superrcooled liquid region $\Delta T_{\mathrm{x}}$ decrease for the alloy with higher $\mathrm{Nb}$ contents. Since alloys showing a high glass forming ability (GFA) often exhibit large $\Delta T_{\mathrm{x}}$, the increasing $\mathrm{Nb}$ content certainly decreases the GFA of the alloys. For the monolithic BMG, there is only one exothermic peak during the heating process, while more exothermic peaks can be seen from the DSC scan of the composites. The $T_{\mathrm{g}}, T_{\mathrm{X}}$ and $\Delta T_{\mathrm{X}}$ of the composites and the monolithic BMG are listed in Table 1.

Microstructural observation on the cross-section of the chemical etched $\mathrm{Zr}_{55} \mathrm{Al}_{8.5} \mathrm{Ni}_{8.5} \mathrm{Cu}_{13} \mathrm{Nb}_{15}$ composites reveals that the phase constitution is influenced by the local cool-

Table 1

$T_{\mathrm{g}}, T_{\mathrm{X}}$ and $\Delta T_{\mathrm{X}}$ of the composites and the monolithic BMG

\begin{tabular}{llll}
\hline Samples & $T_{\mathrm{g}}(\mathrm{K})$ & $T_{\mathrm{x}}(\mathrm{K})$ & $\Delta T(\mathrm{~K})$ \\
\hline BMG composite & 665 & 724 & 59 \\
BMG & 643 & 738 & 95 \\
\hline
\end{tabular}



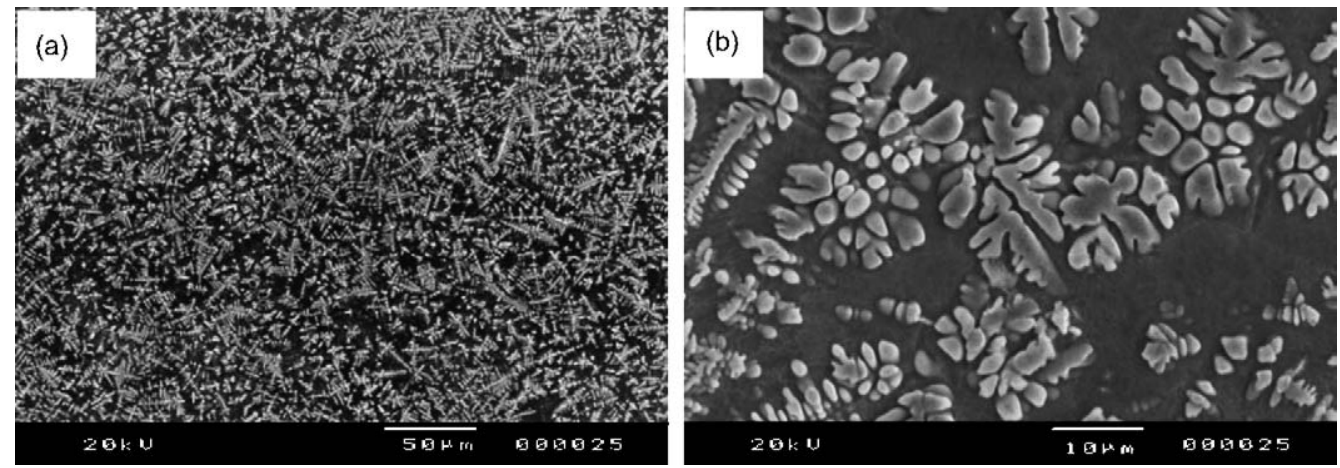

Fig. 3. SEM images of the $\mathrm{Zr}_{55} \mathrm{Al}_{8.5} \mathrm{Ni}_{8.5} \mathrm{Cu}_{13} \mathrm{Nb}_{15}$ BMG composites: (a) morphology of the composites at the center region and (b) dendritic phase at higher magnification.

ing rate. Toward the center of the composite, it is dominated by a high density of dendritic phase embedded in the matrix. While at the outermost area of the composite, a mixed microstructure consisting of quasicrystalline particles and sparsely distributed dendritic phase exists. The distribution of the dendritic phase at the center region of the composite is shown in Fig. 3(a). Fig. 3(b) shows the SEM image of the dendrite at higher magnification. The dendrite structure can be characterized by primary dendrite axes with length of $20-30 \mu \mathrm{m}$ and a radius of about $500 \mathrm{~nm}$. EDS analysis shows that the dendritic phase has a composition of about 60.8 at.\% $\mathrm{Zr}, 6.7$ at.\% $\mathrm{Al}, 3.4$ at.\% Ni, 7.2 at.\% $\mathrm{Cu}$ and 21.9 at. $\% \mathrm{Nb}$, while the glass matrix has a composition of about 49.0 at.\% $\mathrm{Zr}, 12.2$ at.\% $\mathrm{Al}, 14.2$ at.\% Ni, 19.2 at.\% $\mathrm{Cu}$ and 5.4 at. $\% \mathrm{Nb}$. It reveals that the composition of the dendritic phase is depleted in $\mathrm{Ni}$ and enriched in $\mathrm{Zr}$ and $\mathrm{Nb}$. The highest $\mathrm{Nb}$ content of the dendritic phase can reach about 21.9 at.\%, which is much higher than that of the dendritic phase in other Zr-based composites [12,13].

Fig. 4 is the TEM image and corresponding SAED pattern of the dendritic phase. The dendritic phases are highly developed with secondary dendritic arm perpendicular to the primary axes, which can be observed in Fig. 4(a). Fig. 4(b) presents the SAED pattern of the dendritic phase taken along the [1 111 ] zone axis, corroborating the formation of a bcc typed crystalline phase.

The mixed microstructure at the outermost area of the composite is characterized by nano-sized quasicrystals densely distributed at the matrix, together with sparsely distributed dendritic phase. The mixed microstructure is about 200-500 $\mu \mathrm{m}$ thick and toward the center of the samples, only densely distributed dendritic phase was found. The typical microstructure of the co-existed quasicrystals and dendrite is shown in Fig. 5(a). Fig. 5(b) shows the quasicrystals and dendrite at higher magnification, which indicated that there might be a transformation relationship between the two phases. Kühn et al. [12] also indicated that the formation tendency of the quasicrystalline and the bcc phase are closely correlated, which are very sensitively to small modification in chemical composition, cooling rate, etc. Fig. 5(c) is the TEM image of the quasicrystalline particles. The fivefold symmetry SAED pattern of the spherical particles in Fig. 5(d) proves the formation of quasicrystals. However, the quasicrystals are distributed inhomogeneously at the matrix
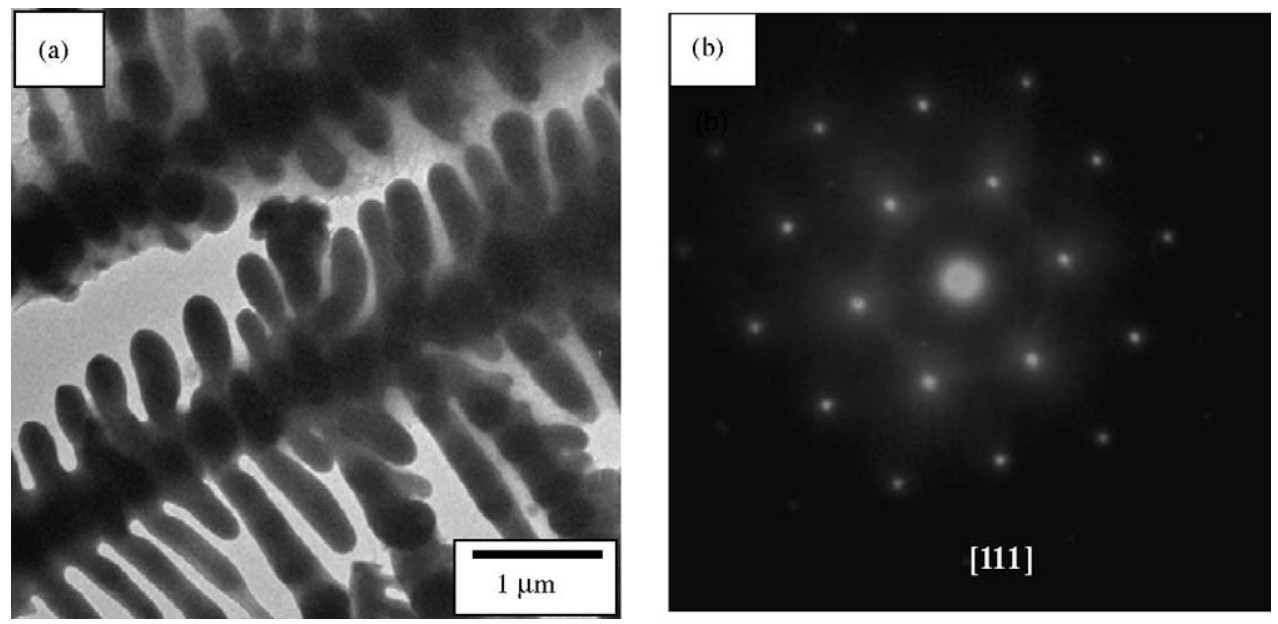

Fig. 4. TEM image and corresponding SAED pattern of the dendritic phase. (a) TEM bright field image of the dendrite phase and (b) SAED pattern of the dendritic phase taken along [ $\left[\begin{array}{lll}1 & 1 & 1\end{array}\right]$ zone axis. 

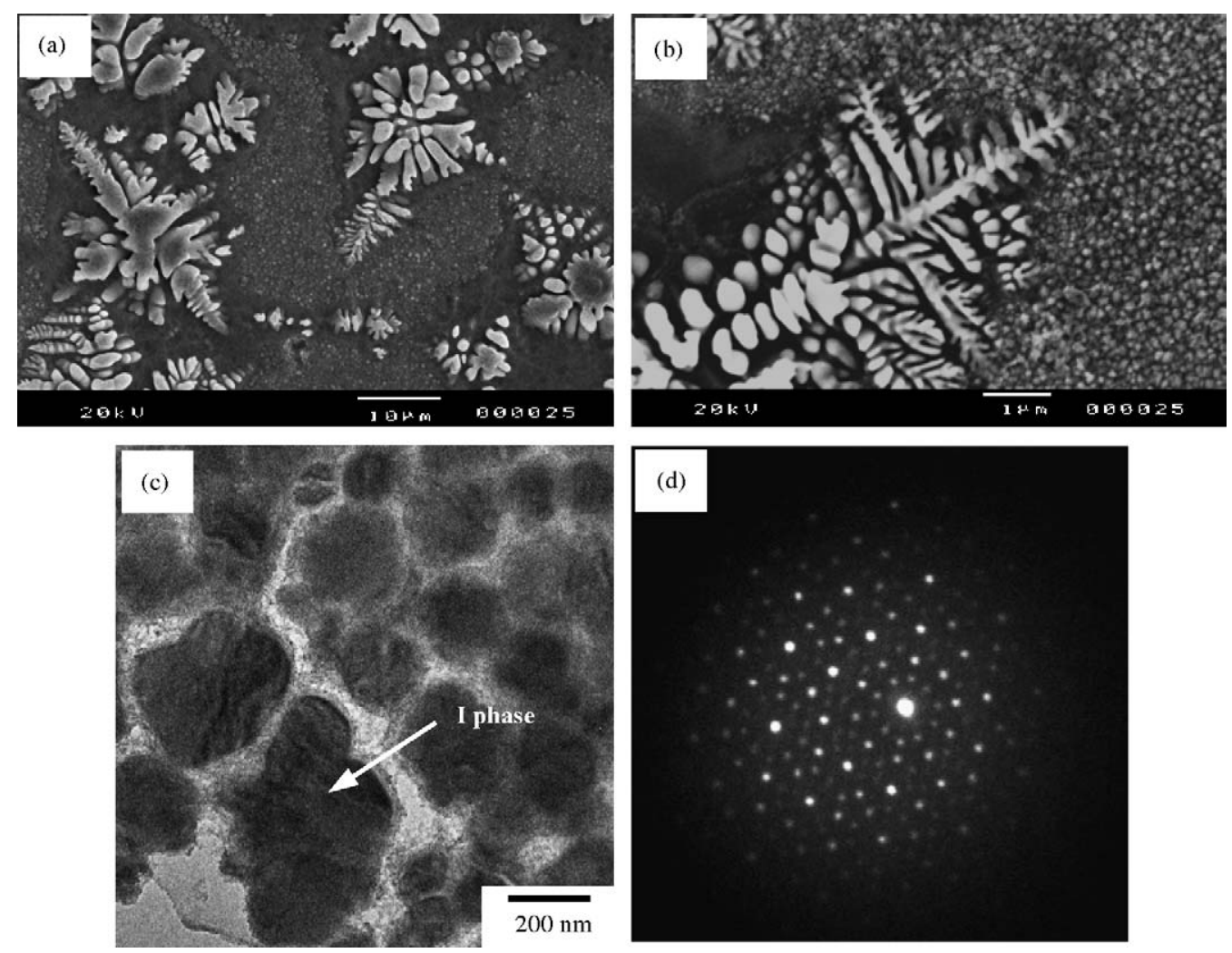

Fig. 5. Microstructure characterization of the $\mathrm{Zr}_{55} \mathrm{Al}_{8.5} \mathrm{Ni}_{8.5} \mathrm{Cu}_{13} \mathrm{Nb}_{15}$ composite: (a and b) SEM image showing the microstructure at the outermost region of the composites, (c) TEM bright field image of the quasicrystalline phase and (d) SAED pattern of the quasicrystalline phase showing five-fold symmetry.

and the volume fraction is too small to be detected by X-ray diffraction.

To verify the ductility of the dendrite phase, a series of nanoindentation tests were conducted on the isolated dendrite and the matrix, respectively. Both the dendrite and the glass matrix were indented to maximum applied load of $100 \mathrm{mN}$ at a same loading rate of $50 \mathrm{mN} / \mathrm{min}$. Fig. 6 shows the typical load-displacement $(h-p)$ curves of the dendrites and its counterpart glass matrix in the $\mathrm{Zr}_{55} \mathrm{Al}_{8.5} \mathrm{Ni}_{8.5} \mathrm{Cu}_{13} \mathrm{Nb}_{15}$ com-

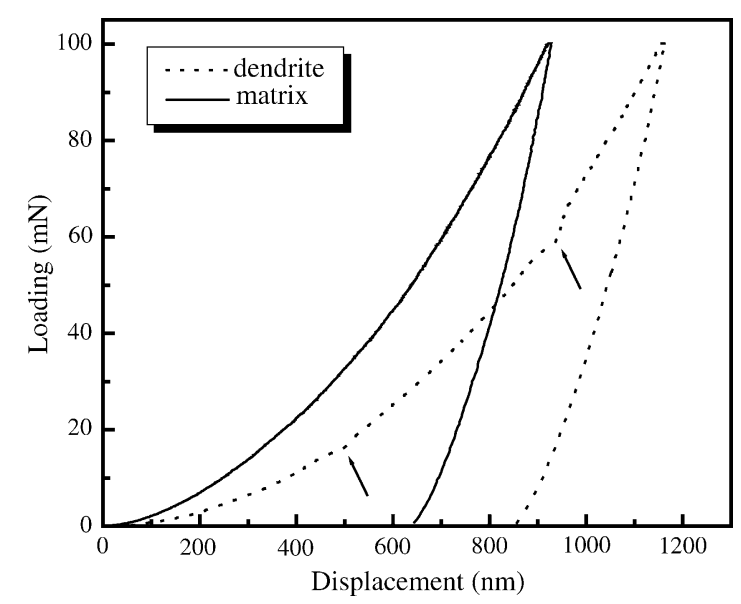

Fig. 6. Load-displacement $(h-p)$ curves after nanoindentation for the dendrite and glass matrix of the $\mathrm{Zr}_{55} \mathrm{Al}_{8.5} \mathrm{Ni}_{8.5} \mathrm{Cu}_{13} \mathrm{Nb}_{15}$ BMG composites. posites. The curves are smooth except one or two pop-in appear on the curves for dendritic phase, which are indicated by arrows in Fig. 6. The maximum displacement of the dendrite and its counterpart matrix are 1159 and $924 \mathrm{~nm}$, respectively. The final displacements of the indenter, namely the permanent depth of penetration after the indenter was fully unloaded, are 856 and $648 \mathrm{~nm}$ for the dendrite and its counterpart matrix, respectively. The permanent depth of the dendrites is much larger than those of the composite matrix. From the $h-p$ curves, the elastic modulus $(E)$ and hardness $\left(H_{\mathrm{v}}\right)$ of the dendrite and the glass matrix can be calculated by Oliver and Pharr method. The calculation results of $E$ and $H_{\mathrm{v}}$ for the dendritic phase and the glass matrix are $78.6 \mathrm{GPa}$ and $4226.3 \mathrm{MPa}, 119.32 \mathrm{GPa}$ and $6842.4 \mathrm{MPa}$, respectively. Fig. 7 gives a representative SEM micrograph showing an indent on the dendrite phase, which is enclosed in a white triangle. It is obvious that the dendrite plastically deformed after indentation. Cracks or slip bands, which is often observed for brittle materials, cannot be found on the dendrite. Therefore, although the pop-in in the curves for dendritic phase may be caused by the interaction between the dendrite and the matrix under loading, the interaction does not influence the confirmation of the ductility of the dendrite phase.

A series of room temperature compression tests were carried out for the as-cast composites and the monolithic glass. Fig. 8 shows the typical compressive stress-strain curves. The monolithic BMG exhibited yielding at about $1949 \mathrm{MPa}$ 


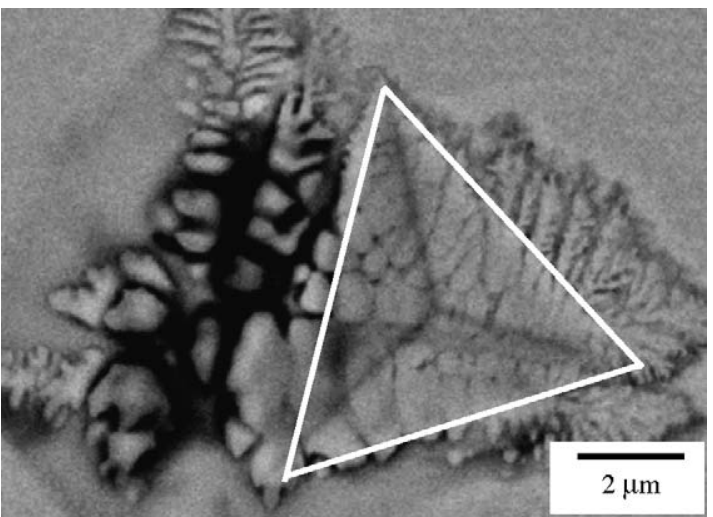

Fig. 7. SEM image showing the indent on the dendrite.

and subsequently followed with strain-softening, which is often occurs for BMGs due to the structural change of the material in the shear bands that leads to a local lowering of the viscosity [17]. Finally, the material demonstrated an ultimate strength of $1867 \mathrm{MPa}$ and fracture strain of about $1 \%$. While for the ductile dendritic phase contained BMG composites, it exhibited catastropic failure under relatively low yielding strength of about $1523 \mathrm{MPa}$ and then fractured without measurable strain hardening or plastic defromation. The deformation behavior of the composites in the present paper is much different with those previously reported composites containing ductile dendritic phase, which undergoes work hardening and obvious plastic deformation prior to failure $[8,9,12,13]$.

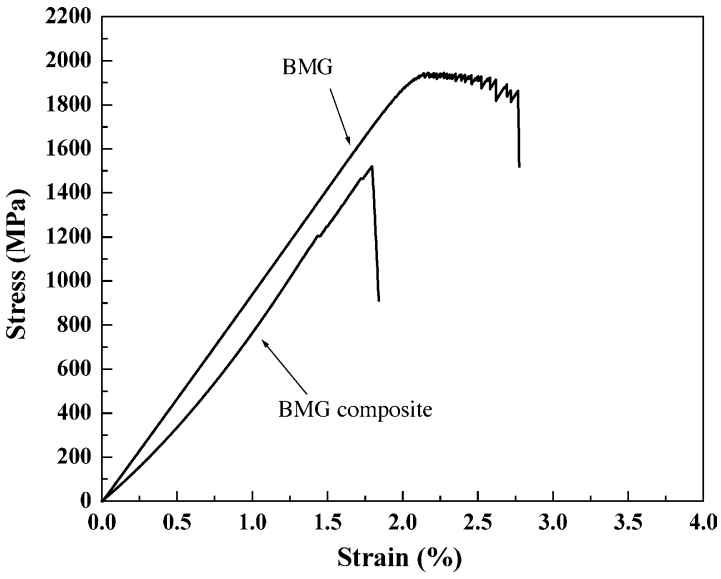

Fig. 8. Stress-strain curves after room temperature compression tests for the composite and the monolithic BMG.

Fig. 9 presents the SEM images showing the typical fracture surface of the $\mathrm{Zr}_{55} \mathrm{Al}_{8.5} \mathrm{Ni}_{8.5} \mathrm{Cu}_{13} \mathrm{Nb}_{15}$ composite. From the general profile of the fractured sample shown in Fig. 9(a), the materials exhibits basically brittle fracture features and seems to follow a distensile mode by which the samples break or form multiple fracture surfaces [18-20]. In the central region of the fracture plane shown in Fig. 9(b), a typical fracture surface for the dendrite/matrix composites is present, exhibiting somewhat ductile characterization. However, in the outermost region of the sample shown in Fig. 9(c), rather brittle fracture features like dim-
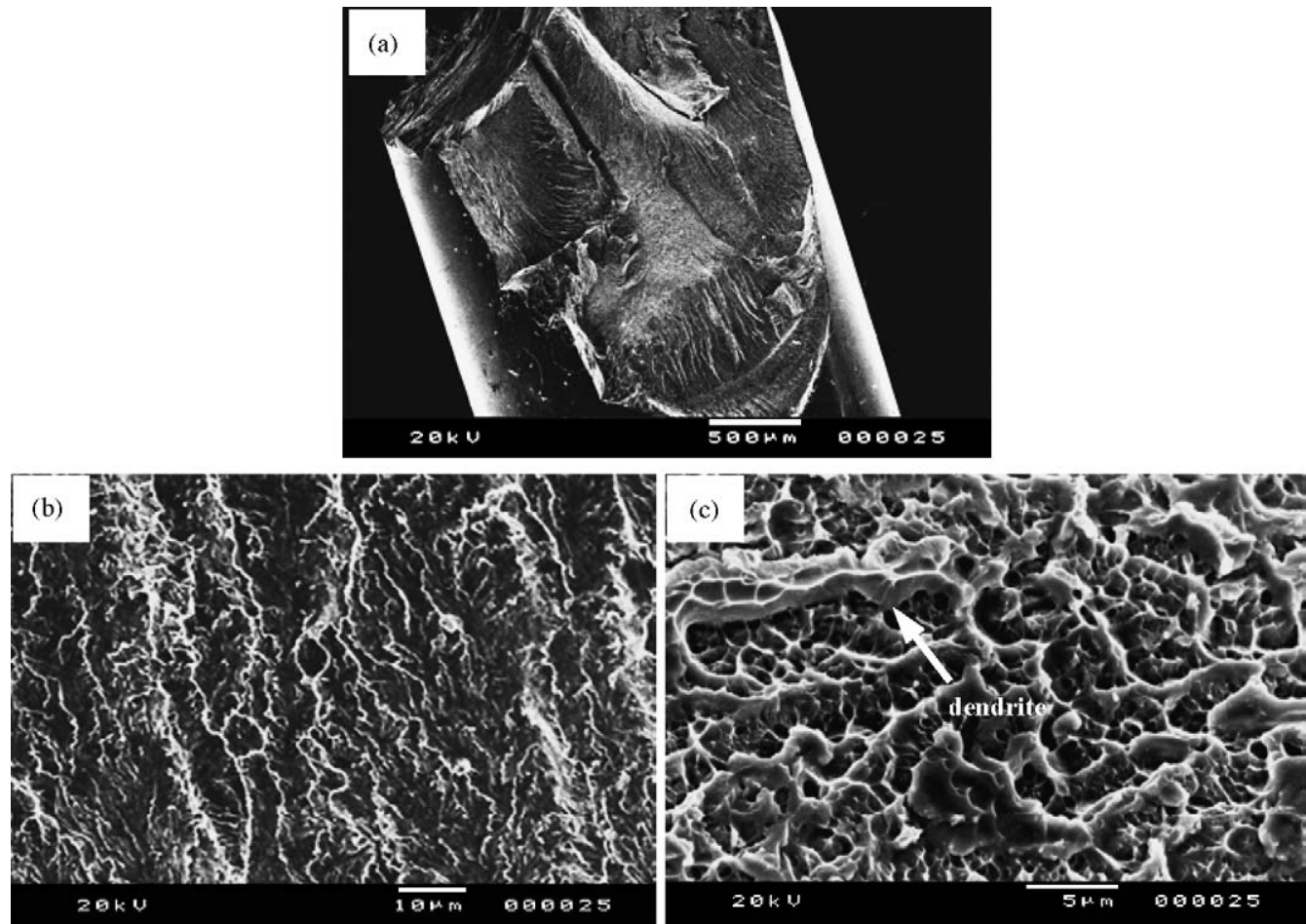

Fig. 9. Fractography of the $\mathrm{Zr}_{55} \mathrm{Al}_{8.5} \mathrm{Ni}_{8.5} \mathrm{Cu}_{13} \mathrm{Nb}_{15}$ composite: (a) general profile of the fractured sample, (b) fracture plane at the center region and (c) fracture plane at the outermost region of the sample. 
ples illustrating particles peeling off from the matrix can be observed.

\section{Discussions}

From the above description, it reveals that the $\mathrm{Zr}_{55} \mathrm{Al}_{8.5}$ $\mathrm{Ni}_{8.5} \mathrm{Cu}_{13} \mathrm{Nb}_{15}$ composite containing ductile dendrite in this paper abnormally exhibits a rather low yielding strength and no plasticity, comparing with the corresponding $\mathrm{Zr}_{63} \mathrm{Al}_{10} \mathrm{Ni}_{10} \mathrm{Cu}_{14} \mathrm{Nb}_{3}$ monolithic BMG. It is well known that the crystals in the glass matrix can significantly influence the flow deformation and fracture behavior of the BMGs, depending on its nature, size, volume fraction and distribution. For example, the plasticity of the BMG composites containing nano-crystals or ceramic particles cannot be improved significantly, but sometimes even display a lower strength and zero plasticity [19]. While for the BMG composites containing ductile dendritic phase, the dendritic phase was assured to contribute to the strain-hardening of the materials by dislocation motion, twinning and phase transformation induced plasticity. Furthermore, the presence of ductile dendritic phase can seed the initiation of organized shear band patterns, confine the propagation of individual shear bands to domains having a spatial scale of the order of the primary dendrite axes length. Therefore, plasticity is distributed more homogeneously in the shear band patterns, which results in high strains to failure of the composites. However, Kühn et al. [13] proposed that only the existence of a ductile dendrite bcc phase is not sufficient for reaching work hardening and significant plastic deformation, because of the necessity of an effective interaction between the microstructural length scale of the dendrites and the length scale of the shear bands. Although we do not know exactly the width of the shear bands in the present paper, the lower yield strength and lack of plasticity is suggested not to be related to the size of the dendritic phase. If this is the case, no plasticity would be improved but its high yield strength can still keep comparable with that of the monolithic BMG.

Based on the above discussions, it is proposed that the precipitation of quasicrystalline particles will bring deleterious effect on the mechanical properties of the materials. The macro-mechanical behavior of the composites is the result of a presence of the microstructural inhomogeneity, namely, the different types of the microstructure. At the outermost region of the sample, the brittle quasicrystalline phases is likely to dominate the deformation behavior, leading to the observed decrease in ductility and low yield strength since the deformation is no longer governed by the deformation mechanism of the amorphous phase. While the center part of the sample still fractured by shear bands mode. Therefore, an inhomogeneous deformation behavior might occur for the composites sample under compression. Although the ductile dendrite distributed at the center of the sample, the area for undertaking the stress are greatly decreased and lead to failure before strain-hardening of the dendrite occurs.

\section{Conclusions}

$\mathrm{Zr}_{55} \mathrm{Al}_{8.5} \mathrm{Ni}_{8.5} \mathrm{Cu}_{13} \mathrm{Nb}_{15}$ BMG composites containing densely distributed dendritic phase were prepared by copper mould cast. The ductility of the dendritic phase was confirmed by nanoindentation tests. However, the composites exhibit rather brittle features under room temperature compression. The formation of the quasicrystalline phase at the outermost part of the rod sample is suggested to lead to the inhomogeneous deformation of the composites, which finally results in catastrophic failure at relatively lower stress. It is proposed that the microstructure homogenization will play a greater effect on the mechanical properties of the composites materials rather than the formation of ductile dendritic phase.

\section{Acknowledgements}

This work was supported by a City University of Hong Kong Strategic Research Grant (Project number: 7001529), Knowledge Innovation Program of Chinese Academy of Sciences (Project number: KJCX2-SW-L05) and National Natural Science Foundation of China (Grant number: 50101012)

\section{References}

[1] H. Choi-Yim, W.L. Johnson, Appl. Phys. Lett. 71 (1997) 3808-3810.

[2] C. Fan, D.V. Louzguine, C. Li, A. Inoue, Appl. Phys. Lett. 75 (1999) 340-342.

[3] C. Fan, A. Inoue, Appl. Phys. Lett. 77 (2000) 46-48.

[4] B. Clausen, S.Y. Lee, E. Üstündag, C.C. Aydiner, R.D. Conner, M.A.M. Bourke, Scr. Mater. 49 (2003) 123-128.

[5] J. Das, A. Güth, H.J. Klauß, C. Mickel, W. Löser, J. Eckert, S.K. Roy, L. Schultz, Scr. Mater. 49 (2003) 1189-1195.

[6] H. Choi-Yim, R.D. Conner, F. Szuecs, W.L. Johnson, Acta Mater. 50 (2002) 2737-2745.

[7] R.D. Conner, R.B. Dandliker, W.L. Johnson, Acta Mater. 46 (1998) 6089-6102.

[8] C.C. Hays, C.P. Kim, W.L. Johnson, Phys. Rev. Lett. 84 (2000) 2901-2904.

[9] F. Szuecs, C.P. Kim, W.L. Johnson, Acta Mater. 49 (2001) 1507-1513.

[10] C.C. Hays, C.P. Kim, W.L. Johnson, Mater. Sci. Eng A 304-306 (2001) 650-655.

[11] K.M. Flores, W.L. Johnson, R.H. Dauskardt, Scr. Mater. 49 (2003) 1181-1187.

[12] U. Kühn, J. Eckert, N. Mattern, L. Schultz, Appl. Phys. Lett. 80 (2002) 2478-2480

[13] U. Kühn, J. Eckert, N. Mattern, L. Schultz, Mater. Sci. Eng. A 375-377 (2004) 322-326.

[14] G. He, J. Eckert, W. Löser, L. Schultz, Nat. Mater. 2 (2003) 33-37.

[15] Q.L. Dai, B.B. Sun, M.L. Sui, G. He, Y. Li, J. Eckert, W.K. Luo, E. Ma, J. Mater. Res. 19 (2004) 2557-2566.

[16] J. Eckert, U. Kühn, N. Mattern, G. He, A. Gebert, Intermetallics 10 (2002) 1183-1190.

[17] F. Spaepen, Acta Metall. 25 (1977) 407-415.

[18] Z.F. Zhang, G. He, J. Eckert, L. Schultz, Phys. Rev. Lett. 91 (2003) 045505 .

[19] Z.F. Zhang, G. He, J. Eckert, Philos. Mag. 85 (2005) 897-915.

[20] G. He, W. Löser, J. Eckert, L. Schultz, Metall. Mater. Trans. A 35 (2004) 1591-1601 